FSS

Cicchirillo, V. J. (2020). The impact of video game character viewpoints and task on perceptions of cognitive and similarity identification. Cyberpsychology: Journal of Psychosocial Research on Cyberspace, 14(4), Article 2. https://doi.org/10.5817/CP2020-4-2

\title{
The Impact of Video Game Character Viewpoints and Task on Perceptions of Cognitive and Similarity Identification
}

\author{
Vincent J. Cicchirillo \\ Graham School of Management, Saint Xavier University, Chicago, Illinois, USA
}

\begin{abstract}
The following study examines the effect of character viewpoints in a video game and task (motivation) on outcomes associated with identification and enjoyment. The study employs a 2 (first-person viewpoint vs. third-person viewpoint) $\times 2$ (task vs. no task) experimental design to test potential theoretical impacts of identification. Specifically, this study looked at how first-person and third-person viewpoints impact identification (cognitive vs. similarity) and enjoyment after playing a video game. The results showed that third-person perspectives through manipulated gaming objectives (task) positively impacted identification. Furthermore, task was associated with higher game play enjoyment. This study adds to the current literature by comparing different type's identification (cognitive vs. similarity) and how these concepts are impacted by point-of-view and motivation. Thus, extending our theoretical understanding of identification.
\end{abstract}

Keywords: Cognitive identification; similarity identification; third-person; first-person; video games

\section{Introduction}

Video game playing has become quite a popular activity with American society. According to the Entertainment Software Association (ESA) (2019) sixty-five percent of American households play video or computer games on a daily basis. Research on video games often goes back and forth between a debate on positive and negative effects (see Anderson et al., 2010; DeCamp \& Ferguson, 2017; Ferguson \& Kilburn, 2010; Gabbiadini et al., 2017; Greitemeyer \& Mügge, 2014). The types of outcomes that are elicited from playing video games may be impacted by contextual factors of the game. One such factor that might have an impact upon game play outcomes is point of view (POV). Researchers have examined the extent to which POV impacts aggressive outcomes (Farrar et al., 2006; Krcmar \& Farrar, 2009) and psychophysiological responses (Lim \& Reeves, 2009). The current research will examine POV's and task's effects upon two forms of identification (cognitive \& similarity) and enjoyment. Early research on video games (Schneider et al., 2004) explored the concept of identification, defined as, "a mechanism through which audience members experience reception and interpretation of the text from the inside, as if the events were happening to them" (p. 245).

Identification is multifaceted concept. For instance, there are two different ways to look at identification with media characters, that of cognitive identification (Cohen, 2001) and that of similarity identification (Feilitzen \& Linné, 1975). 'Cognitive' identification with a media character is based upon a cognitive connection between an audience member and that media character such that the individual empathizes with and takes the perspective of that character (Cohen, 2001). Similarity identification is a process by which viewers reinforce their identities through important character aspects (Cicchirillo \& Appiah, 2014). Thus, for similarity identification to take place an individual must look outside of their person to the media representation and assess levels of similarities between 
that character and themselves. One context of video games that might affect identification and enjoyment is of character viewpoints. This study adds to the current literature by comparing different type's identification (cognitive vs. similarity) and how these concepts are impacted by point-of-view and motivation. Moreover, this research focuses upon two distinct forms of 'media' identification that of cognitive identification (Cohen, 2001, 2006) and concepts of similarity identification. It is noted that similarity identification and Cohen's identification are actually confused with one another (see Moyer-Guse \& Nabi, 2010). Cohen's concept of identification and dimensions seems uniquely different inherently from similarity identification. Few research studies measure the constructs laid out by Cohen (absorption, empathy, motivation, \& understanding) and instead use constructs that reflect more similarity identification. As such this study will include these dimensions in measurement and analysis.

\section{POV in Video Games}

Contextual features of video games have the potential to impact how players experience that game and subsequently their responses to stimuli afterwards. Point-Of-View (POV) is an internal component of playing video games. Video games may vary on whether players control their characters through first-person or third-person viewpoints or perspectives. First-person viewpoints are that the individual takes on the characters (or avatars) perspective through seeing just their hands/arms on the screen (Farrar et al., 2006; Krcmar \& Farrar, 2009). The player assumes they are the character and only see disembodied hands and arms. First-person viewpoints may lead to higher levels of identification because those viewpoints don't lead to a differentiation between themselves and the character. However, some researchers have noted that first-person viewpoints may lead to a no-person perspective (Krcmar \& Farrar, 2009). The player doesn't see themselves outside of the characters' perspective as they might in a third-person viewpoint. First-person viewpoints allow the player to see the environment through the character's eyes (Farrar et al., 2006). Thus, the player does not see the character's body just their arms and anything they may be holding. On the other hand, third-person viewpoints allow the player to see the characters' entire body and control game play (and their character) from just a few steps away (Farrar et al., 2006). Farrar et al. (2006) examined how third vs. first-person viewpoints and representations of blood in a video game impact post-game play outcomes associated with aggression. POV in a gaming context may have different effects because they may impact a sense of involvement or immersion that are created through those perspectives.

For instance, Farrar et al. (2006) found that third-person (not first-person) viewpoints had a greater impact upon players focus and involvement during game play. This was somewhat counter to what was expected. The researchers noted that "it is possible that when players do not see the main character (as is the case in first-person play), it may appear to the gamer that there is no protagonist (antagonist?)" (Farrar et al., 2006, p. 400). This effect was further tested looking through the theoretical lense of the general aggression model GAM (Krcmar \& Farrar, 2009). Aggressive cognitions and affect may be impacted via POV and moderate its impact upon retaliatory aggression in an experimental setting. The results of this extension showed that individuals who played in the third-person viewpoint had more violent cognitions and those cognitions in turn moderated aggressive outcomes (Krcmar \& Farrar, 2009). Lim and Reeves (2009) tested the effect of POV on skin conductance, arousal, and presence. The researchers argued that first-person viewpoints allow a more visualized immediacy and should have an impact upon arousal (Lim \& Reeves, 2009). However, this effect may be attenuated by whether individuals choose their own avatar or are assigned an avatar. Players maybe more engaged when choosing their own avatars and thus in the case of third-person viewpoints experience heighted effects of arousal and presence. The results showed contingent effects depending upon character choice. Lim and Reeves (2009) found that avatar (character) choice and third-person viewpoints had a greater impact upon heart rate. On the other hand, first-person viewpoints with no avatar choice lead to increased presence. Thus, there is some evidence to suggest there are differing effects based upon POV manipulations.

It should be noted that the above mentioned studies did not specifically test identification and did not manipulate narrative elements (motivations) that might have an effect upon these types of outcomes. However, some of these researchers have noted that identification may be a process that can impact these outcomes. For instance, Krcmar and Farrar (2009) noted that in first-person viewpoints no character exists, individuals do not see a person for identification to take place (Krcmar \& Farrar, 2009). It could be that different points-of-view may impact identification differently. Moreover, the current state of research offers little examination of whether third-person or first-person viewpoints can have a significant impact upon identification. This research sets out to specifically 
test POV and motivation (task) in narrative video game and how it impacts two forms of identification (cognitive vs. similarity).

\section{Cognitive Identification vs. Similarity Identification}

Cohen's theoretical conceptualization of identification was created within a broader context of media. Thus, character identification with television, movie, or sports figures. Cohen's $(2001,2006)$ conceptualization of identification is that individuals must take on the perspective of that character wherein self and other (i.e., character) are no longer differentiated. Cohen's $(2001,2006)$ conceptualization of a four-dimensional identification construct includes empathy, cognition, motivational, and absorption. This conceptualization of identification takes an internal view of characters' perspective rather than an external view. This shift from feeling about a character to feeling with a character is a large factor in self-identification in video game play and has been explored further by various researchers such as Klimmt et al. (2009); Klimmt et al. (2010); and Przybylski et al. (2012).

Klimmt et al. (2009) define video game identification as a concept wherein the player adopts the characters goals and values. This concept involves a transfer of one's identity from self to character. Klimmt et al. (2009) note that this conceptualization of identification involves theories of self-perceptions and self-concepts from social psychological perspectives. Furthermore, it was noted that video game identification is distinctly different from other media forms of identification (TV, books, etc...) because of the interactivity associated with video games. Klimmt et al. (2009) noted that video game players may experience a monadic character relationship form of identification wherein the player merges with the character. This experience is different from other forms of media in which a viewer has a dyadic relationship that clearly separates themselves form the character/protagonist. The interactive experience of video games serves as a catalyst that helps move from dyadic to monadic. Klimmt et al. (2010) examined identification through implicit measurements in a first-person shooter compared to a racing game. Furthermore, Klimmt et al. (2010) note that a shift from self to character can occur automatically and impact individual's information processing even unconsciously. The researchers measured participant's cognitive associations (through implicit associations) that would be associated with their character's self-concept. Thus, playing as a soldier in a military game should, through identification, lead to higher self-perceptions of military concepts. On the other hand, "concepts unrelated to the character the players have identified with would not be associated more strongly with 'me"' (Klimmt, et al., 2010, p. 326). The results of their study show support for cognitive identification in that individuals through cognitive associations may take on the self-perceptions of their character. It should be noted that Klimmt et al. (2010) found this effect through first-person viewpoints as a gaming manipulation. Cognitive identification has a distinct theoretical argument against similarity perceptions as a form of identification. Cohen (2001) states that "similarity is associated with a judgment of realism; identification, on the other hand, does not foster any judgments that require treating a character as external to the self" (p. 254).

The concept of similarity has at times been equated with identification (Hoffner \& Cantor, 1991). Similarity or perceived similarity with a media character may be based upon physical and psychological attributes. Thus, individuals can use relevant cues such as race (Cicchirillo \& Appiah, 2014; Eastin et al., 2009) or physical appearance (Hoffner \& Buchanan, 2005; Hoffner \& Cantor, 1991) in identifying with a media character. Eastin (2006) examined the extent to which cueing gender of character in a violent video game context impacted outcomes associated with aggression and presence. The research showed that when self-gender and character gender matched (among female players) it positively impacted both presence and aggressive thoughts. Although, it should be noted that identification was not specifically tested in this context. Eastin et al. (2009) found evidence that race of character positively impacted identification in a violent video game. The researchers found that white players identified more strongly with black characters in a violent video game. This finding seems counterintuitive in the context of similarity identification. However, the players may consciously or unconsciously identify with the stereotype of African-Americans as violent and aggressive (Eastin et al., 2009). Thus, similarity perceptions do not need to be a perfect match in physical attributes in order to lead to identification.

Similarity identification as mentioned relies on individuals making comparisons between themselves and others. In this case it's the similarity between themselves and their character. This form of identification is a process by which viewers reinforce their identities and recognize themselves in that character through salient characteristics (Chory-Asad \& Cicchirillo, 2005; Eastin et al., 2009). Thus, for similarity identification to take place an individual must look outside of their person to the media representation and assess levels of similarities between that 
character and themselves. Specifically related to video games, Williams (2011) conducted an experiment in which participants 'skinned' (creating a character physically similar to oneself) video game characters and then played a violent video game with that character. The results of this study found that skinning did lead to higher levels of identification and high reported levels of state hostility (Williams, 2011). Similarity identification may be heightened because of third-person viewpoints. In order to further understand how third-person viewpoints may impact perceptions of similarity identification we must look towards early theorizations of identification. For instance, Kelman's $(1958,1961)$ identification theory states that individuals will assess their level of similarity with a source and make subsequent judgments based upon the level of that similarity. In this conceptualization the more the perceived similarity the more favorable the evaluations and effects of that identification. Similarity need not be appearance, but the goals and attitudes of that character. Kelman's $(1958,1961)$ theory of identification also holds that individuals internalize the attitudes and beliefs of a character. According to Brown (2015), "media consumers empathize with and put themselves in the place of a persona and then adopt the persona's beliefs and goals, thus positing perceived homophily as an important attribute of identification" (p. 264). Here third-person viewpoints may allow individuals to empathize with a character that they can visualize since they can actually see that person on screen. As mentioned previously, research showed that third-person viewpoints positively impacted focus (Farrar et al., 2006) and cognitions (Krcmar \& Farrar, 2009). Therefore, it was assumed that third-person viewpoints would have a greater effect upon similarity identification and cognitive identification.

H1a: Individuals who play a video game in a third-person viewpoints will report a higher sense of similarity identification than will individuals who play the game in first-person viewpoints.

H1b: Individuals who play a video game in a third-person viewpoints will report a higher sense of cognitive identification than individuals than will individuals who play the game in first-person viewpoints.

\section{Motivation in Gaming Contexts}

In the context of gaming, motivation is the goal directed behavior of one's character in the game. Individuals may have various motives for playing games (see Yee, 2006). However, in this examination motivation is looking at how task allocation - giving a player a small short-term gaming goal - may impact identification. Video games offer both brief short-term goals and motivations (completing a level) to larger goals such as beating the game or level. The narrative nature of video games enables individuals to understand and potentially identify with the motives of their character. Missions may be viewed as short-term goals or tasks, while the narrative may be viewed as the long game, the long-term goal. Lee et al. (2006) noted that narrative elements such achieving goals or overcoming conflicts enable players the proper motivations for their characters' actions. Video games may better offer intrinsic motivations over external motivations. For instance, completing a video game or beating a level offers a reward that is rewarding in and of itself rather than external validation. Video games certainly offer intrinsically satisfying experiences (Ryan et al., 2006). Theoretically speaking, Self-Determination Theory (SDT) offers predictions on how both intrinsic and extrinsic can promote or undermine motivation (Ryan \& Deci, 2000). Intrinsic motivations are shown to be strongly related to video game play (Ryan et al., 2006) as players advancement and achievements garnered from play result from their own self-satisfaction in completion. Thus, individuals may play video games because the reward is playing the game in and of itself over some external reward.

Researchers have further noted that there may be a connection between motivations and identification. Przybylski et al. (2012) examined the extent to which video games offer intrinsic motivation because players may identify with their characters. The researchers argued that "game self-ideal-self convergence would be linked to high levels of intrinsic motivation" (Przybylski et al., 2012, p.70). Przybylski et al. (2012) did find that identification (convergence between game-self \& ideal-self) predicted intrinsic motivation. Research demonstrates that when participants feel congruency between themselves and their characters in terms of characteristics such as personality, they are more likely to experience intrinsic motivation (Przybylski et al., 2012). The construct of ideal-self used by Przybylski et al. (2012) more closely resembles similarity identification as it requires participants to assess their game-self, who they are while playing the video game compared to who they are outside of the game. As such Przybylski's conceptual construct of self is somewhat divergent from the conceptualizations of identification provided by Cohen (2001). 
In a more direct examination of Cohen's conceptualization of identification, Li and Lwin (2016) set out to develop an exergame motivational model based upon the influence of one's self and their avatar. The researchers noted that players may take on the goals of their avatar and noted that "seeing his or her avatar in the game evokes emotions and empathy as the character progresses through the game" (Li \& Lwin, 2016, p. 352). More importantly, if the character achieves in the game, the player may then identify with the character on a motivational level (Li \& Lwin, 2016). The results garnered through a longitudinal experimental study did show that identification was directly connected to motivation (exergame intention) (Li \& Lwin, 2016). Van Reijmersdal et al. (2013) examined how women identify with and are motivated to play female centric video games. The researchers note that both identification and motivation are key components of game play processes and outcomes. The results through a large scale survey of young female game players found that identification is a positive predictor of game play motivations (challenge, interest, social interaction, \& escapism) (van Rejimersdal et al., 2013). Although, the audience is somewhat different from the current study their results (van Rejimersdal et al., 2013) show that conceptually identification is related to motivation. Overall, this research (Li \& Lwin, 2016; van Rejimersdal et al., 2013) shows that identifying with your avatar in-game can have positive impacts on motivation. However, here we want to see if giving players a task (motivation) can lead to a higher sense of identification and not the other way around. The relationship between motivation and identification has been clearly established (Li \& Lwin, 2016; Przybylski et al., 2012; van Rejimersdal et al., 2013). However, what happens if motivation comes before identification. For instance, Schneider et al. (2004) found that when playing a video game with a story compared to one with no-story players were more likely to identify with their characters. Certainly, in video games individuals new to the game may first need to learn the narrative of the game in order to understand the tasks that are being completed. This narrative understanding may then help to realize their characters motivation, which in turn can lead to identifying with that character. Therefore, it was expected that:

\section{H2a: Motivation (task) will predict higher levels of similarity identification than no task.}

H2b: Motivation (task) will predict higher levels of cognitive identification than no task.

Also, there should be an interaction between motivation (task) and POV to predict identification. Given the research that shows heightened effects of third-person POV's (Farrar et al., 2006; Krcmar \& Farrar, 2009) and motivation (Przybylski et al., 2012; van Rejimersdal et al., 2013) it was expected that identification should increase when participants have both a task and play in a third-person viewpoint. As mentioned previously, Li and Lwin (2016) examined how aspects such as self-presence, identification, and enjoyment impacted motivation to exergame and exercise through motion-sensing games. The results of their analysis showed that presence positively impacts identification, which then impacts motivation through enjoyment. There was also a direct relationship between identification and exergame intention (i.e., motivation) (Li \& Lwin, 2016). Experimentally, the motion-sensing games chosen by Li and Lwin (2016) were both third-person perspective games (see Just Dance 3 \& Kinect Sports). A theoretical underpinning that might help connect POV and motivation to identification are mental models. Farrar et al. (2006) noted that "mental models are cognitive representations of events or situations, including the people, concepts, settings, and interrelations involved" (p. 389). In essence, mental models are cognitive scripts that individuals can learn from and enact that impact attitudinal and behavioral outcomes (McGloin et al., 2016). Theoretically it also involves aspects of social cognitive theory (Bandura, 2002) in which individuals can learn from observing others. Furthermore, mental models are malleable and can help us interpret media representations, which makes them applicable to video game experiences (McGloin et al., 2016). One particular aspect of mental modeling is called model matching and involves the evaluation of the games content with real world situations (Boyan \& Sherry, 2011). If individuals can see their characters, it can represent an observable model of a cognitive representation. Thus, the 'player' learns about that character and create mental models of their behavior in conjunction with that character's motivations. Theoretically, if a person can view their character (i.e., third-person viewpoint) and understand their characters motivations (task) then they can create mental models of that character. These mental models can then be used when assessing their level of identification of that character. If the mental model is easier to enact and remember because a person can readily see that person in mind then it can be suggested that a third-person viewpoint may have a greater effect than a first-person viewpoint. Therefore, it is expected that third-person viewpoints (POV) will have stronger impacts upon identification than a first-person viewpoint when given a task. 
H3a: Individuals who play a game in a third-person viewpoint and are given a task will report higher levels of similarity identification. Thus, there should be an interaction between POV and task. Thus, there should be an interaction between POV and task on similarity identification.

H3b: Individuals who play a game in a third-person viewpoint and are given a task will report higher levels of cognitive identification. Thus, there should be an interaction between POV and task on cognitive identification.

While a majority of research has focused upon the negative or aggressive outcomes of POV and violent video games (see Farrar et al., 2006; Krcmar \& Farrar, 2009), little research has examined the alternative side of POV on entertainment. Clearly, video games are a form of entertainment media; the psychological appeal of playing these games is that they evoke a pleasurable experience (Raney et al., 2006). Monterio et al. (2018) examined how different POV's in a VR game influenced presence, simulator sickness, and enjoyment. While this research is divergent in a number of areas it sheds light on a possible relationship between POV and enjoyment. The researchers conducted an experiment in which participant's played a racing game in either first-person perspective-VR, third-person perspective-VR, and conventional third-person perspective (Monterio et al., 2018). The results of this study showed that both types of VR perspectives elicited positive experiences, however the third-person perspective in the conventional display generated the most enjoyment and was preferred over both VR-perspectives (Monterio et al., 2018). Thus, we can see that potentially a third-person perspective can generate more enjoyment over other perspectives. Thus, it was predicted that:

\section{H4: POV will be positively related to enjoyment.}

As mentioned previously, video games can offer strong intrinsic motivations (see Ryan et al., 2006), which are predicted to impact identification. The elicitation of intrinsic motivation may also strongly impact enjoyment when playing a video game. For instance, Ryan et al. (2006) found a connection between need satisfaction and enjoyment that results from playing a video game. Peng et al. (2012) conducted experimental research to test how need satisfaction factors related to intrinsic motivation impact enjoyment, motivation, and engagement. The results showed that factors related to intrinsic motivation such as competence and autonomy positively impacted both enjoyment and motivation for future play (Peng et al., 2012). Also, as previously mentioned POV will be related to enjoyment, it makes sense that task will also be related to higher enjoyment. Thus, multiple studies show that intrinsic motivation generated from game play is associated with enjoyment (Peng et al., 2012; Ryan et al., 2006; Tamborini et al., 2010). It was then predicted that:

H5: Motivation (task) will predict higher levels of enjoyment than no-task.

Furthermore, other studies have shown a strong connection between identification and enjoyment. For instance, Li and Lwin (2016) found that identification strongly predicted enjoyment. Conceptually, Klimmt et al. (2009) noted that identification with a video game character may be better linked to enjoyment over other non-interactive forms of media in that a player takes on the actions of their character. Trepte and Reinecke (2010) conducted an experiment in which they manipulated competitiveness and avatar-player similarity based on personality. The results of this study found that a strong player-avatar similarity was positively related to identification, which in turn was positively related to enjoyment. However, when controlling for identification the researchers found that player-avatar similarity did not positively impact enjoyment (Trepte \& Reinecke, 2010). Thus, identification generated from game play is more important than the conditions in which it was generated. It was predicted that:

H6: Both forms of identification (similarity and cognitive) will be positively related to enjoyment.

\section{Methods}

The data was collected from 85 undergraduate students at a large southwestern university. Each individual received extra credit for participation. Students were recruited from that Universities participant pool. A total of 55 men and 30 women participated with an average age of 20 years old. Twenty-nine percent were freshman, $51 \%$ were Sophomores, $14 \%$ juniors, and $4 \%$ were seniors. In terms of gaming experience, all participants reported playing a video game before (although, not this particular game). In terms of frequency of game play participants 
reported: $7 \%$ never, $34.1 \%$ less than once a month, $4.7 \%$ once a month, $11.8 \% 2-3$ times a month, $8.2 \%$ once a week, $22.4 \%$ 2-3 times a week, and $11.8 \%$ daily. So overall, the majority of participants play more sporadically.

\section{Procedure}

The following study employed a 2 (third-person viewpoint vs. first-person viewpoint) $\times 2$ (task vs. no task) between subjects experimental design. Participants played the video game Grand Theft Auto: V (GTA V), for approximately 15 minutes. GTA V is a video game produced by Rockstar North games. The game (PC version) allows for players to play either in first-person of third-person viewpoints during actual game play. Thus, this game was chosen to allow for a consistent manipulation of viewpoints (third vs. first). Furthermore, GTA V is deemed to be set in realistic setting of San Andreas and Los Santos, which are based upon cities in California (Sawyer, 2012). In order to test and see if POV and task can impact identification it was determined that a game that had a more realistic story line and settings was best to allow for identification to occur. Research has shown that a match between the gaming experience and content of the game is important for individuals to enact mental models when playing (Shafer et al., 2014). Participants signed up for experimental slots online and reported to a computer lab on campus. Once at the lab participants were asked to complete a short pretest about basic demographics and prior game playing habits. After participants were done, they were taken over to the computer (in the same room) and asked to play the game for 15 minutes. Players used a gaming controller (similar to console systems) to play the game on the PC version. This allowed for mimicry similar to console-based play. Before participants entered the room, the gaming manipulations were set-up (POV \& task). First, players were randomly assigned to either the first-person or third-person viewpoint and randomly assigned to either the task or no task condition. The task was manipulated through asking participants to read over a brief narrative of the game and then read their assignment for game play (task). In the no task condition players still read over the narrative, but were not given a specific task to complete once game play started.

\section{Dependent Measures}

\section{Cognitive Identification}

Cognitive identification was measured using the four factors of Cohen's (2001) identification (empathy, understanding, motivation, \& absorption). Each factor was measured on a 5-point Likert-type scale ranging from Strongly Disagree (score $=1$ ) to Strongly Agree (score $=5$ ). Absorption was measured using three items assessing the degree to which participants felt immersed in the gaming environment $(M=2.15, S D=0.58, a=.80)$. Empathy was measured using four-items assessing how much participants felt the emotions of their character $(M=1.98$, $S D=0.72, a=.80$ ). Motivation was measured using three-items assessing the degree to which players internalized the character's objectives (ex. I understood the reasons why the characters did what they did) $(M=1.93, S D=0.53$, $a=.74)$. Finally, Understanding was measured using two-items assess the extent to which participants took the perspective of their character (ex. I was able to understand the events in the game in a way similar to my character) $(M=1.87, S D=0.58, a=.74)$.

\section{Similarity Identification}

Similarity identification was measured using five-items assessing the degree to which participants felt they were similar to their character. This included items related to background, lifestyle, dress, and appearance. Items were assessed on a 5-point Likert-type scale $(M=1.66, S D=0.83, a=.80)$.

\section{Enjoyment}

Enjoyment was measured using self-assessment items relating to participant's happiness, enjoyment, and entertainment after game-play (ex. I feel happy, I feel entertained, etc.). The items were assessed on 5-point Likerttype scales $(M=2.70, S D=0.43, a=.82)$. 


\section{Results}

Hypotheses one through five were tested using SPSS and the dependent variables were examined within Multiple Analysis of Variance model (MANOVA). Hypothesis six was tested using multiple regression. Given the effects of gender and POV on outcomes, gender was included as a covariate (Farrar et al., 2006). Lim and Reeves (2009) also examined potential differences between player gender and POV. The results of their analyses showed minimally significant differences for a POV $\times$ gender interaction. Specifically, the results showed that POV $\times$ gender impacted skin conductance, but there were no significant differences for heart rate, presence, arousal, or valence (Lim \& Reeves, 2009). Thus, there are divergent results, but enough to keep gender as a potential covariate.

The results for $\mathrm{H} 1 \mathrm{a}$ and $\mathrm{H} 1 \mathrm{~b}$ showed no significant main effect for third-person viewpoints on similarity identification $F(1,85)=0.060, p=.936$. or any cognitive identification dimensions, empathy $F(1,85)=0.12, p=.730$, absorption $F(1,85)=0.079, p=.779$, understanding $F(1,85)=0.194, p=.661$, and motivation $F(1,85)=1.26, p=.273$. These were all non-significant. $\mathrm{H} 2 \mathrm{a}$ and $\mathrm{H} 2 \mathrm{~b}$ predicted that there will be a main effect for the task condition for both forms of identification. The results were supported for similarity identification $F(1,85)=8.97, p<.05, \eta_{\mathrm{p}}^{2}=$ .096 , supporting $\mathrm{H} 2 \mathrm{a}$. The results showed that task condition was higher for similarity identification $(M=2.00, S D$ $=0.90)$ than the no task condition $(M=1.37, S D=0.64)$. Also, the results were supported for cognitive identification $F(1,85)=12.02, p<.01, \eta_{p}^{2}=.12$, supporting $\mathrm{H} 2 \mathrm{~b}$. Individuals who played the task condition reported higher cognitive identification dimensions of absorption, understanding, motivation, and empathy than individuals in the no-task condition (see Table 1 for mean comparisons). Post-hoc analyses reveal that the means were significantly different for absorption $(p=.004)$, understanding $(p=.043)$, motivation $(p=.002)$, and empathy $(p=.028)$.

Table 1. Means and Standard Deviations for Cognitive Identification Dimensions by Task Condition.

\begin{tabular}{|c|c|c|c|c|c|c|}
\hline \multirow{2}{*}{ Cognitive Identification } & \multicolumn{2}{|c|}{ Task } & \multicolumn{2}{|c|}{ No-Task } & \multirow{2}{*}{$F(1,85)$} & \multirow{2}{*}{$\eta^{2}$} \\
\hline & $M$ & $S D$ & $M$ & $S D$ & & \\
\hline Absorption & 2.34 & 0.443 & 1.98 & 0.662 & $8.65^{\star \star}$ & .10 \\
\hline Understanding & 1.74 & 0.423 & 1.53 & 0.464 & $4.23 *$ & .05 \\
\hline Motivation & 2.12 & 0.454 & 1.74 & 0.544 & $10.19 * *$ & .11 \\
\hline Empathy & 2.19 & 0.722 & 1.79 & 0.684 & $5.03^{*}$ & .05 \\
\hline
\end{tabular}

Table 2. Means and Standard Deviations for Similarity and Cognitive Identification by POV and Task Conditions.

\begin{tabular}{|c|c|c|c|c|c|c|}
\hline & \multirow{2}{*}{$\frac{\text { Condition }}{\text { POV }}$} & \multicolumn{2}{|c|}{ Task } & \multicolumn{2}{|c|}{ No-Task } & \multirow{2}{*}{$F(1,85)$} \\
\hline & & $M$ & $S D$ & $M$ & $S D$ & \\
\hline \multirow[t]{2}{*}{ Similarity Identification } & Third-Person & 2.02 & 0.89 & 1.33 & 0.55 & 0.500 \\
\hline & First-Person & 1.89 & 0.92 & 1.37 & 0.77 & \\
\hline \multicolumn{7}{|l|}{ Cognitive Identification } \\
\hline \multirow[t]{2}{*}{ Absorption } & Third-Person & 2.31 & 0.45 & 2.03 & 0.67 & 0.484 \\
\hline & First-Person & 2.36 & 0.44 & 1.92 & 0.66 & \\
\hline \multirow[t]{2}{*}{ Understanding } & Third-Person & 2.05 & 0.46 & 1.74 & 0.67 & 0.578 \\
\hline & First-Person & 1.90 & 0.63 & 1.79 & 0.56 & \\
\hline \multirow[t]{2}{*}{ Motivation } & Third-Person & 2.15 & 0.50 & 1.84 & 0.59 & 0.372 \\
\hline & First-Person & 2.09 & 0.40 & 1.62 & 0.47 & \\
\hline \multirow[t]{2}{*}{ Empathy } & Third-Person & 2.27 & 0.58 & 1.79 & 0.65 & 0.511 \\
\hline & First-Person & 2.10 & 0.84 & 1.78 & 0.73 & \\
\hline
\end{tabular}

Note. None of these interactions were significant. 
Hypothesis $3 a$ and $3 b$ predicted that there will be a significant interaction effect between third-person viewpoints and task for similarity identification and cognitive identification respectively. Hypothesis 3a was not supported for similarity identification $F(1,85)=0.500, p=.482$. Also, there were no significant effects for any cognitive identification dimensions, empathy $F(1,85)=0.511, p=.477$, absorption $F(1,85)=0.484, p=.489$, understanding $F(1,85)=0.578, p$ $=.449$, and motivation $F(1,85)=0.372, p=.544$ (see Table 2 for means).

Hypothesis four predicted a significant main effect for POV on enjoyment. The results supported this hypothesis $F(1,85)=4.58, p<.05, \eta_{p}^{2}=.05$. Individuals in the third-person viewpoint reported higher enjoyment $(M=2.80, S D$ $=0.39)$ than individuals in the first-person viewpoint $(M=2.61, S D=0.56)$. However, Post-Hoc analysis revealed a significant interaction between POV and Task for enjoyment $F(1,85)=8.13, p=.006, \eta_{\mathrm{p}}^{2}=.09$. When examining the estimated marginal means we see that participants in the third-person viewpoint with a task condition $(M=2.90)$ reported higher enjoyment than individuals in third-person viewpoint with no-task condition $(M=2.29)$ (see Figure 1 for chart). Hypothesis five predicted a significant main effect for task on enjoyment. The results supported this hypothesis $F(1,85)=7.39, p<.05, \eta_{p}^{2}=.13$. Individuals in the task condition reported higher enjoyment $(M=2.86$, $S D=0.31)$ than the no-task condition $(M=2.55, S D=0.57)$.

Figure 1. Interaction Between Task and Point of View on Enjoyment.

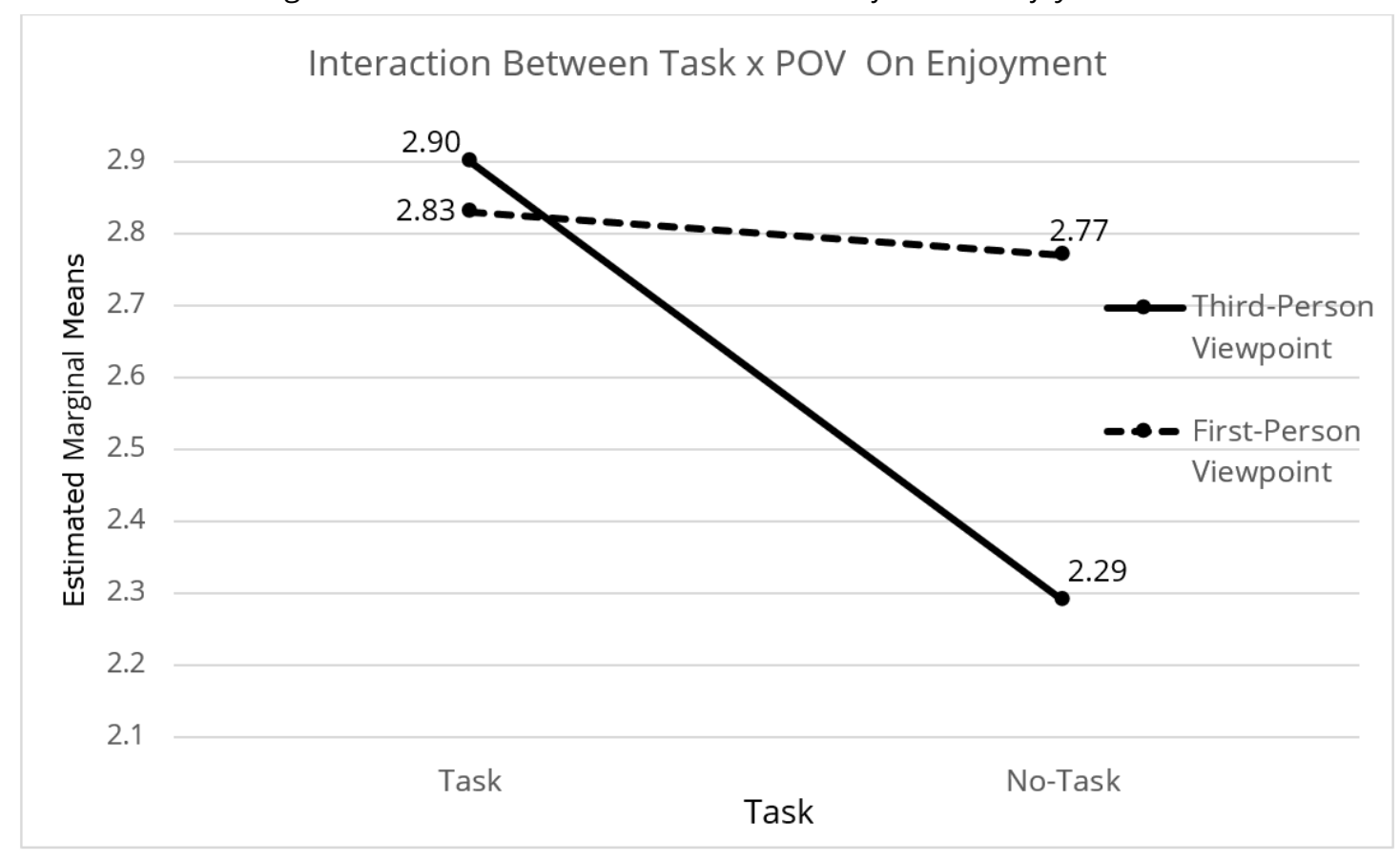

Finally, hypothesis six predicted a significant relationship between enjoyment and both similarity identification and cognitive identification. In order to test for this relationship a multiple regression was run with enjoyment as the dependent variable and similarity identification and the dimensions of cognitive identification as the predictors. This hypothesis was partially supported as the results indicated that there was a significant effect between enjoyment, absorption, and motivation $\left(F(5,83)=9.09, p<.001, R^{2}=.36\right)$. The individual predictors were examined and showed that absorption $(b=0.44, p<.001)$ and motivation $(b=0.28, p=.023)$ were positive predictors of enjoyment.

\section{Discussion}

This study set out to examine how third-person and first-person viewpoints and task (motivation) may impact different forms of identification (cognitive vs. similarity). Furthermore, it goes beyond current examinations by comparing different conceptual types of identification (cognitive vs. similarity). Researchers have noted that conceptually there exists some variance between considerations of identification (Klimmt et al., 2009). As mentioned previously, researchers have often confused the two types of identification (Moyer-Guse \& Nabi, 2010). Also, few researchers have included Cohen's distinct dimensions of cognitive identification (i.e., Absorption, empathy, motivation, \& understanding). This study set out to include those dimensions against perceptions of similarity identification. The results of this study showed that there were strong main effects for task upon both 
forms of identification. Researchers have noted that motivation in the gaming context can positively predict associations and convergence between game self and ideal self (Przybylski et al., 2012). Thus, if a player feels motivation in the gaming environment, they are more likely to take on the characteristics of that avatar. The results of this study showed that task positively impacted similarity identification and certain dimensions of cognitive identification. Although, the understanding dimension of cognitive identification was not significant the means were in the expected direction. It has been noted that video games are linked to intrinsic motivations (Ryan \& Deci, 2000), which are shown to be overall stronger and more motivating than extrinsic motivations. Simply adding a task in a video game creates a sense of drive that allows a player to take on the identity of a character. This result is in line with research that supports a link between motivation and identification (Li \& Lwin, 2016; van Rejimersdal et al., 2013). What is particularly interesting is that motivation (task) impacts both forms of identification. The results showed strong effects in that motivation may be a factor that can impact identification. As mentioned previously, research has shown that narratives given to individuals about their characters helps enhance game play outcomes (Schneider et al., 2004). It could be suggested that motivation can come before identification. Research certainly supports notions that when a player identifies with their character it results in stronger motivations (Li \& Lwin, 2016; Przybylski et al., 2012). However, if the individual is new to the game, they may need to understand their characters motivations before being able to identify with that character. In this study some individuals were given a brief explanation of our characters situation (narrative) and a task to perform when playing. The results do suggest that individuals in this task condition reported higher levels of identification and enjoyment after playing the game. Thus, under certain conditions motivation can lead to identification. Furthermore, the potentially heightened effects of third-person viewpoints can be supported through research by Hoffner and Buchanan (2005) that found both extrinsic characteristics of a character and intrinsic personality characteristics can impact identification. Thus, relevant external cues (gender, appearance, dress, etc.) and relevant internal cues (motivation for behavior) can positively predict identification. If players feel similar to their character and are strongly motivated to play the game, then both forms of identification are likely to occur. This result would seem in line with contentions that identification can take the form of social psychological perspectives of self-perception theory (Klimmt et al., 2009).

Furthermore, it was expected that task (motivation) and POV would positively impact enjoyment. Both task and POV were found to positively impact enjoyment. Video games are a form of entertainment medium and playing them may offer an intrinsic reward for playing. The research by Przybylski and colleagues (2012) supports the intrinsic motivations of playing games. While the game that participants played in this study was violent, it may also offer rich media experiences that give to positive outcomes over negative outcomes. It was shown that thirdperson viewpoints did impact enjoyment. Research has shown heightened effects for third-person viewpoints (Farrar et al., 2006; Krcmar \& Farrar, 2009) over first-person viewpoints. Therefore, these results are somewhat in line with past findings. Third-person viewpoints offer players the opportunity to see their character and make judgements about whether that character or avatar is similar to themselves. In the context of video games individuals assess their level of similarity with an avatar/character which impacts their identification with that character. Researchers have noted that perceived similarity can positively impact identification (Williams, 2011, 2013).

However, post-hoc analyses showed a significant interaction between these conditions (POV $\times$ task) to predict enjoyment. As such, individuals who played the game in a third-person viewpoint with a task showed significantly higher enjoyment than the other conditions. Researchers have noted a potential connection between third-person viewpoints and enjoyment (Monterio et al., 2018) as well as a connection between motivation in-game to predict enjoyment (Peng et al., 2012). Thus, it would make sense that the combination of these conditions results in higher enjoyment. It could be that seeing our avatar/character carry out the tasks results in a sense of greater satisfaction than just seeing disembodied hands perform the task (first-person viewpoint). Moreover, a significant driver of enjoyment, might be the identification generated from playing the game regardless of point-of-view. The results showed that identification was found to positively predict enjoyment. If players identify with their characters, then they are more likely to enjoy playing that game. Researchers have noted that the identification linked to enjoyment from playing a game is stronger than the situation that created that identification (Trepte \& Reinecke, 2010). 


\section{Theoretical Implications}

Theoretically speaking Cohen's identification $(2001,2006)$ is often more associated with cognitions and emotions than similarity perceptions. Cohen's conceptualization is a more robust construct. It is a multifaceted construct that includes aspects related to perspective taking (understanding), emotions (empathy), immersion (absorption), and motivation with a character (Cohen, 2001). This view of identification is that players shift their identities from themselves to their character's identities. They take on the role of the character and lose a sense of self outside of the environment. Motivation was shown to impact aspects of Cohen's identification as well as perceptions of similarity identification more so than point of view. As was shown, POV did not have any direct or interaction effects with both forms of identification. On the other hand, task (motivation) did elicit both main and interaction effects for identification and enjoyment. Thus, motivation may be a significant driver of creating identification with a gaming character. Theoretically, Kelman's $(1958,1961)$ early conceptualizations of identification can help explain how motivation may impact identification and not the other way around. Individuals evaluate the attitudes and behaviors of characters before evaluating their identification with that character. Granted this early conceptualization was in line with books and movies and not video games. As noted prior Brown (2015) suggested that newer forms of media allow individuals to adopt a persona's beliefs and goals then gaining a sense of identification with that character. As such, giving a game player small tasks or goals during game play (which is common) helps build a sense of purpose, which can then help individuals identify with that character. Certainly, future research should look towards longitudinal research to examine this link.

\section{Conclusions \& Limitations}

This study shows important considerations and extensions of how motivation and POV may specifically affect identification in conjunction with other contextual factors of video games. Furthermore, how motivation may positively impact identification. Moreover, these results may also allude that both similarity identification and cognitive identification maybe complimentary to one another rather than divergent to one another. One limitation of the current study was that narrative (story) was held consistent across the conditions. All participants read a story narrative about the game. This may have impacted how players experienced the game and in turn identified with their character. Future research should examine the potential impact that POV, task, and narrative may upon identification. While the game chosen was violent other genres of games should be considered for examination. Can this effect be replicated with non-violent video games?

\section{References}

Anderson, C. A., Shibuya, A., Ihori, N., Swing, E. L., Bushman, B. J., Sakamoto, A., Rothstein, H. R., \& Saleem, M. (2010). Violent video game effects on aggression, empathy, and prosocial behavior in Eastern and Western countries. Psychological Bulletin, 136(2), 151-173. https://doi.org/10.1037/a0018251

Bandura, A. (2002). Social cognitive theory of mass communication. In J. Bryant \& D. Zillmann (Eds.), LEA's communication series. Media effects: Advances in theory and research (pp. 121-153). Lawrence Erlbaum Associates.

Boyan, A. \& Sherry, J. L. (2011). The challenge in creating games for education: Aligning mental models with game models. Child Development Perspectives, 5(2), 82-87. https://doi.org/10.1111/j.1750-8606.2011.00160.x

Brown, W. J. (2015). Examining four processes of audience involvement with media personae: Transportation, parasocial interaction, identification, and worship. Communication Theory, 25(3), 259-283.

https://doi.org/10.1111/comt.12053

Chory-Assad, M., \& Cicchirillo, V. (2005). Empathy and affective orientation as predictors of identification with television characters. Communication Research Reports, 22, 151-156.

Cicchirillo V., \& Appiah O. (2014). The impact of racial representations in video game contexts: Identification with gaming characters. New Media and Mass Communication, 26, 14-21.

https://www.iiste.org/Journals/index.php/NMMC/article/view/13685 
Cohen, J. (2001). Defining identification: A theoretical look at the identification of audiences with media characters. Mass Communication and Society, 4(3), 245-264. https://doi.org/10.1207/S15327825MCS0403_01

Cohen, J. (2006). Audience identification with media characters. In J. Bryant \& P. Vorderer (Ed.) Psychology of entertainment (pp. 183-197). Lawrence Erlbaum Associates.

DeCamp, W. \& Ferguson, C. J. (2017). The impact of degree of exposure to violent video games, family background, and other factors on youth violence. Journal of Youth \& Adolescence, 46(2), 388-400.

https://doi.org/10.1007/s10964-016-0561-8

Eastin, M. S. (2006). Video game violence and the female game player: Self- and opponent gender effects on game presence and aggressive thoughts. Human Communication Research, 32(3), 351-372.

https://doi.org/10.1111/j.1468-2958.2006.00279.x

Eastin, M. S, Appiah, O., \& Cicchirillo, V. (2009). Identification and the influence of cultural stereotyping on postvideogame play hostility. Human Communication Research, 35(3), 337-356. https://doi.org/10.1111/j.14682958.2009.01354.x

Entertainment Software Association. (2019). Essential facts about the computer and video game industry (2019). http://www.theesa.com/about-esa/industry-facts/

Farrar, K. M., Krcmar, M., \& Nowak, K. L. (2006). Contextual features of violent video games, mental models, and aggression. Journal of Communication, 56(2), 387-405. https://doi.org/10.1111/j.1460-2466.2006.00025.x

Feilitzen, C., \& Linné, O. (1975). Identifying with television characters. Journal of Communication, 25(4), 51-55. https://doi.org/10.1111/j.1460-2466.1975.tb00638.x

Ferguson, C. J., \& Kilburn, J. (2010). Much ado about nothing: The misestimation and overinterpretation of violent video game effects in Eastern and Western nations: Comment on Anderson et al. (2010). Psychological Bulletin, 136(2), 174-178. https://doi.org/10.1037/a0018566

Gabbiadini, A., Bushman, B. J., Riva, P., Andrighetto, L., \& Volpato, C. (2017). Grand Theft Auto is a "sandbox" game, but there are weapons, criminals, and prostitutes in the sandbox: Response to Ferguson and Donnellan (2017). Journal of Youth \& Adolescence, 46(12), 2460-2466. https://doi.org/10.1007/s10964-017-0731-3

Greitemeyer, T., \& Mügge, D. O. (2015). "Video games do affect social outcomes: A meta-analytic review of the effects of violent and prosocial video game play": Corrigendum. Personality and Social Psychology Bulletin, 41(8), 1164-1164. https://doi.org/10.1177/0146167215591992

Hoffner, C., \& Buchanan, M. (2005). Young Adults' wishful identification with television characters: The role of perceived similarity and character attributes. Media Psychology, 7(4), 325-351.

https://doi.org/10.1207/S1532785XMEP0704_2

Hoffner, C., \& Cantor, J. (1991). Perceiving and responding to mass media characters. In J. Bryant \& D. Zillman (Eds.), Responding to the screen: Reception and reaction processes (pp. 63-101). Lawrence Erlbaum Associates.

Kelman, H. C. (1958). Compliance, identification, and internalization: Three processes of attitude change. Journal of Conflict Resolution, 2(1), 51-60. https://doi.org/10.1177/002200275800200106

Kelman, H. C. (1961). Processes of opinion change. Public Opinion Quarterly, 25(1), 57-78. https://doi.org/10.1086/266996

Klimmt, C., Hefner, H., \& Vorderer, P. (2009). The video game experience as "true" identification: A theory of enjoyable alterations of players' self-perception. Communication Theory, 19(4), 351-373.

https://doi.org/10.1111/j.1468-2885.2009.01347.x 
Klimmt, C., Hefner, D., Vorderer, P., Roth, C., \& Blake, C. (2010). Identification with video game characters as automatic shift of self-perceptions. Media Psychology, 13(4), 323-338.

https://doi.org/10.1080/15213269.2010.524911

Krcmar, M., \& Farrar, K. (2009). Retaliatory aggression and the effects of point of view and blood in violent video games. Mass Communication and Society, 12, 115-138.

Lee, K. M., Park, N., \& Jin, S.-A. (2006). Narrative and interactivity in computer games. In P. Vorderer \& J. Bryant (Eds.), Playing video games: Motives, responses, and consequences (pp. 259-274). Lawrence Erlbaum Associates.

Li, B. J., \& Lwin, M. O. (2016). Player see, player do: Testing an exergame motivation model based on the influence of the self avatar. Computers in Human Behavior, 59, 350-357. https://doi.org/10.1016/j.chb.2016.02.034

Lim, S., \& Reeves, B. (2009). Being in the game: Effects of avatar choice and point of view on psychophysiological responses during play. Media Psychology, 12(4), 348-370. https://doi.org/10.1080/15213260903287242

McGloin, R., Farrar, K. M., Krcmar, M., Park, S., \& Fishlock, J. (2016). Modeling outcomes of violent video game play: Applying mental models and model matching to explain the relationship between user differences, game characteristics, enjoyment, and aggressive intentions. Computers in Human Behavior, 62, 442-451.

https://doi.org/10.1016/j.chb.2016.04.018

Monteiro, D., Liang, H.-N., Xu, W., Brucker, M., Nanjappan, V., Yue, Y. (2018). Evaluating enjoyment, presence, and emulator sickness in VR games based on first- and third-person viewing perspectives. Computer Animation and Virtual Worlds, 29(3-4), Article e1830. https://doi.org/10.1002/cav.1830

Moyer-Guse, E., \& Nabi, R. L. (2010). Explaining the effects of narrative in an entertainment television program: Overcoming resistance to persuasion. Human Communication Research, 36(1), 26-52.

https://doi.org/10.1111/j.1468-2958.2009.01367.x

Peng, W., Lin, J.-H., Pfeiffer, K. A., Winn, B. (2012). Need satisfaction supportive game features as motivation determinants: An experimental study of self-determination theory guided exergame. Media Psychology, 15(2), 175-196. https://doi.org/10.1080/15213269.2012.673850

Przybylski, A. K., Weinstein, N., Murayama, K., Lynch, M. F., Ryan, R. M. (2012). The ideal self at play: The appeal of video games that let you be all you can be. Psychological Science, 23(1), 69-76.

https://doi.org/10.1177/0956797611418676

Raney, A. A., Smith, J. K., \& Baker, K. (2006). Adolescents and the appeal of video games. In P. Vorderer \& J. Bryant (Eds.), Playing video games: Motives, responses, and consequences (pp. 165-180). Lawrence Erlbaum Associates.

Ryan, R. M., \& Deci, E. L. (2000). Self-determination theory and the facilitation of intrinsic motivation, social development, and well-being. American Psychologist, 55(1), 68-78. https://doi.org/10.1037/0003-066X.55.1.68

Ryan, R. M., Rigby, C. S., \& Przybylski, A. (2006). The motivational pull of video games: A self-determination theory approach. Motivation and Emotion, 30(4), 347-363. https://doi.org/10.1007/s11031-006-9051-8

Sawyer, L. (2019, October 8th). GTA V locations that are based on real-life. GameRant.

https://gamerant.com/grand-theft-auto-v-locations-real-life/

Schneider, E. F., Lang, A., Shin, M., \& Bradley, S. D. (2004). Death with a story: How story impacts emotional, motivational, and physiological responses to first-person shooter video games. Human Communication Research, 30(3), 361-375. https://doi.org/10.1111/j.1468-2958.2004.tb00736.x 
Shafer, D. M., Carbonara, C. P., \& Popova, L. (2014). Controller required? The impact of natural mapping on interactivity, realism, presence, and enjoyment in motion-based video games. Presence, 23(3), 267-286.

https://doi.org/10.1162/PRES_a_00193

Tamborini, R., Bowman, N. D., Eden, A., Grizzard, M., \& Organ, A. (2010). Defining media enjoyment as the satisfaction of intrinsic needs. Journal of Communication, 60(4), 758-777. https://doi.org/10.1111/j.14602466.2010.01513.x

Trepte, S., \& Reinecke, L. (2010). Avatar creation and video game enjoyment: Effects of life-satisfaction, game competitiveness, and identification with the avatar. Journal of Media Psychology, 22(4), 171-184.

https://doi.org/10.1027/1864-1105/a000022

van Reijmersdal, E. A., Jansz, J., Peters, O., \& van Noort, G. (2013). Why girls go pink: Game character identification and game-players' motivations. Computers in Human Behavior, 29(6), 2640-2649.

https://doi.org/10.1016/j.chb.2013.06.046

Williams, K. D. (2011). The effects of homophily, identification, and violent video games on players. Mass Communication and Society, 14(1), 3-24. https://doi.org/10.1080/15205430903359701

Williams, K. D. (2013). The effects of video game controls on hostility, identification, and presence. Mass Communication and Society, 16(1), 26-48. https://doi.org/10.1080/15205436.2012.661113

Yee, N. (2006). Motivations for play in online games. CyberPsychology \& Behavior, 9(6), 772-775. https://doi.org/10.1089/cpb.2006.9.772

\section{Correspondence to:}

Vincent J. Cicchirillo

Saint Xavier University, Graham School of Management

3825 West 103rd Street

Chicago, IL 60655

The United States

Email: cicchirillo(at)sxu.edu

Editorial record: First submission received on June 17, 2019. Revisions received on February 5, 2020 and June 4, 2020. Accepted for publication on August 24, 2020.

Editor in charge: Kristian Daneback

\section{About Authors}

Vincent Cicchirillo, PhD is an Assistant Professor of Marketing at Saint Xavier University. He has worked as an assistant professor at the University of Texas at Austin \& DePaul University. His work focuses upon the study of media technologies, in particular the influence of video game play features and contexts on post-game play outcomes. This research extends to advergaming, gamification, and in-game advertising effects upon consumers and players. 